\title{
The Influence of Fluid Temperature on the Entrance Length of Developing Flow in the Upstream Pipe of Measuring Devices
}

\author{
M. H. Alashker \\ Volume and Fluid Flow \\ Metrology Laboratory, \\ National Institute of \\ Standards (NIS) \\ Giza, Egypt
}

\author{
M. E. Elrefaie \\ Department of \\ Mechanical \\ Engineering, Faculty \\ of Engineering, \\ Al-Azhar University \\ Cairo, Egypt
}

\author{
I. M. Shabaka \\ Department of \\ Aerospace \\ Engineering, Faculty \\ of Engineering, \\ Cairo University \\ Giza, Egypt
}

\author{
G. Mohamed \\ Materials and Force \\ Metrology laboratory, \\ National Institute of \\ Standards \\ Giza, Egypt
}

\begin{abstract}
The effect of temperature-dependent viscosity on the flow development behavior inside a circular pipe was studied. The development of centerline axial velocity is presented at different axial positions throughout the tail straight pipe of test section by measurements carried out experimentally using Pitot tube and computed numerically using ANSYS FLUENT 16 software code. The measurements were conducted for various flow rates depending on the control valve opening at two different temperature of fluid $30^{\circ} \mathrm{C}$ and $60^{\circ} \mathrm{c}$. It was found that the computational results showed a good trend agreement with the experimental results. The influence of heat on the density and viscosity of fluid leads to increasing flow rate and Reynolds number. Therefore, it was observed that the hydrodynamic entrance length $(\boldsymbol{L} e)$ has been increased due to heating the fluid. The length $\boldsymbol{L} e$ was increased by $21.4 \%$ for the lower flow rate, which is more than the percentage obtained for the higher flow rate. The results also show that the values of centerline velocity for a fully developed region under heated conditions have been changed slightly compared to unheated conditions. Ultimately, a proper placement of the flow measuring device was determined to measure the flow rate accurately.
\end{abstract}

Keywords: Developing pipe flow; Hydrodynamic entrance lengths; fully developed; Heating effect; CFD; Flow meter; Calibration.

\section{INTRODUCTION}

Accurate flow measurement has an appreciable and significant influence on the management of any type of fluid systems which daily measures rates of heated fluids. Any error in the measurements may cost the consumer lots of money if the error has not been corrected. For this reason, there is interest to find any information that improves the accuracy of flow measurements.

Particularly, the hot fluid is used in critical applications such as thermal fluid system, calibration systems, and crude oil transportation. As the fluid temperature rises, fluid viscosity and density decreases. The average speed of the molecules in a liquid increases with raising the fluid temperature. Consequently, the fluidity tends to be fast. The Reynolds number changes due to the change in velocity, density, and viscosity. For example, the high viscosity of crude oil causes high-pressure drop along pipelines. This requires larger energy and a higher cost of transportation. The heating of the crude oil is one method of several technologies used to improve flow properties. The heated crude oil is transported economically, but the flow rate must be measured accurately.

Therefore, it is of interest to find the effect of fluid temperature on the development of the entrance length for developing flow in a pipe. This hydrodynamic entrance length is defined as the distance of pipe required to have flow with constant velocity profile, after which installation of the flow measuring device is recommended. The accurate flow measurement in a circular pipe is located at the fully developed region. The starting location of the fully developed flow is determined by many criteria. The most commonly used criterion is the location where the centerline axial velocity reaches 99 percent of the fully developed value [1],[2]. Knowledge of the entrance length of the pipe before the fully developed flow region upstream of the measuring device is important. The non-varying velocity profile in the axial direction has long been recognized to get steady flow without any fluctuations in order to achieve a chance for accurate flow measurements [3].

Developing laminar flows in circular tubes have been studied for two different types of oil while the tube is subjected to constant heat flux. For the same wall heat flux, the effect of viscosity variation on the development of centerline axial velocity is greater at low Reynolds number because of the lower velocities. The effect of viscous dissipation consistently increases with Brinkman number of constant heat flux $\mathrm{Br}=\left(\mu \mathrm{ur}^{*} / \mathrm{q}_{\mathrm{w}} \mathrm{D}\right)$, which is a dimensionless number related to heat conduction from a wall to a flowing viscous fluid, where $\mu$ is the dynamic viscosity, $u$ is average flow velocity, $q_{\bar{m}}$ is the wall heat flux and $\mathrm{D}$ is the pipe diameter [4].

Shivani T. Gajusingh and M. H. K. Siddiqui [5] provided the comparison of velocity profiles of flow in the presence and absence of bottom heating wall of a square channel under the same operating conditions at varies mass flow rates. The results showed that both mean streamwise velocity and velocity profiles are affected by wall heating. Furthermore, the influence of wall 
heating on the flow behavior is different for laminar and turbulent flows. The magnitudes of mean streamwise velocity component for the unheated conditions are greater than that for heated conditions when the heat was added from below for turbulent flow cases, but the opposite trend is observed for laminar flow cases in the close vicinity of the wall. The results also showed that the laminar flow becomes turbulent with heat addition due to a reduction in density and viscosity of the fluid.

Nicholl [6] studied the effects of heating on a fully turbulent boundary layer for stable and unstable stratification at low Reynolds numbers of air in a wind tunnel. The difference between the temperatures of the wind tunnel wall and free stream ranged from 20 to $100{ }^{\circ} \mathrm{C}$. He observed that for unstable case (heated floor or roof), the mean velocity near the inlet upstream of the heated plate are larger in magnitude with respect to the velocities further far downstream of the heater.

Keisuke and Masamoto [7] studied the effect of unstable thermal stratification on the flow structure in the wall region between horizontal parallel plates. They measured longitudinal velocity (velocity in horizontal $\mathrm{x}$-direction), vertical velocity (velocity in the vertical y-direction) and temperature fluctuations in the wall region of fully developed turbulent flow for a range of Reynolds and Richardson numbers. They observed that in the wall region of $y^{+}<50$, the longitudinal velocity fluctuations increase with an increase in the instability of stratification (Richardson number) but the vertical velocity fluctuations decrease in the region of $\mathrm{y}^{+}<75$. In the outer region of $y^{+}>100$, the longitudinal velocity fluctuations are almost constant. The trend of the vertical velocity fluctuations increases with increasing instability of stratification, on the contrary, the case at region $y^{+}<75$. They also found that unstable stratification has no effect on the temperature fluctuation in the region of $y^{+}<25$ but the intensity of temperature fluctuations increases slightly with the Richardson number in the outer region. The wall coordinate, $\mathrm{y}^{+}$is a dimensionless distance and an accurate way of determining the distance from the wall to specific data point in the velocity profile.

This literature survey indicates that the flow structure and velocity are highly affected by the addition of heat to the fluid. Consequently, the required length for developing the flow along the pipe is affected by heating the fluid.

Lynn et al [8] used S-type Pitot tube to obtain fluid velocity profiles and average velocity at the center of high water tunnel facility (HWTF, High pressure water tunnel facility) at low flow rates with velocity range $5-30 \mathrm{~cm} / \mathrm{s}$ and compared the Pitot tube measurements with the Particle imaging velocimetry (PIV) measurements in the center of the HWTF to confirm the Pitot tube results in this region. It was found, as shown in Figure 1, that the Pitot tube results showed satisfactory trend and agreement with PIV results.

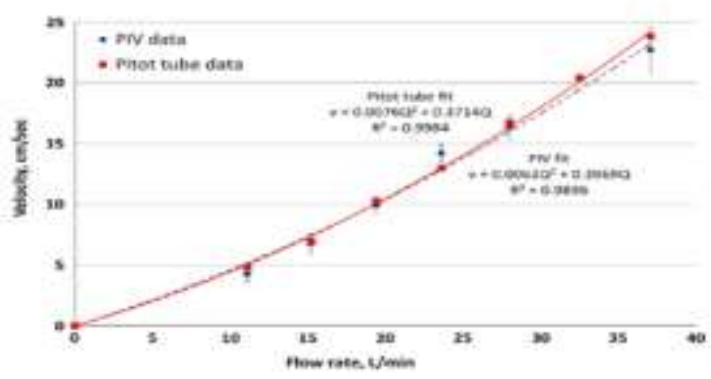

Figure 1 Verification of Pitot tube velocity accuracy by comparing it with PIV measurement [8].

Boetcher and Sparrow [9] demonstrated the error of Pitot tubes for measurements of low flow rate by experimental study at low Reynolds number. They showed that the viscous effect becomes considerable for $\operatorname{Re}<100$ causes a change of the pressure coefficient $C_{p}=\left(p_{x \rightarrow n g}-p_{-} / 0.5 p w^{Z}\right)$ by $2 \%$. this change corresponds to $2-5 \%$ velocity error for $\mathrm{Re}<50$. The pressure coefficient is a parameter used to study the flow of incompressible fluids such as water, where $p_{x=2}$ is the stagnation pressure, $p_{-}$is free stream static pressure, $\rho$ is the fluid density and $w_{-}$is the uniform flow velocity.

Buscarini, et al [10] showed that the calibration coefficient $C_{d}$ of pitot tube used to correct the value of velocity using this equation $V_{i}=\left(C_{x} \sqrt{24 p / p}\right)$, where $V_{i}$ is the velocity at point $\bar{i}, \Delta \mathrm{P}$ is the measured differential pressure between total pressure and static pressure at point $i$ and $\rho$ is the fluid density. They found that the value of $C_{a}$ varies with Reynolds number, usually most variation happens at lower Reynolds numbers and the $C_{a}$ may be greater than 1.0. For high Reynold number, the $C_{d}$ varies between 0.88 and 0.86 with a mean value of 0.87 .

Sotero and Brentan [11] computed the water flow rate based on the centerline velocity which was determined using Pitot tube and compared the results of the physical model with results of computational fluid dynamics (CFD) model to obtain a correction factor. They calculated the average flow velocity $V_{\text {mors }}$, and the centerline velocity $V_{f_{\text {crs }}}$ from the CFD model and defined a

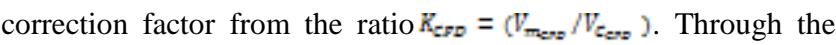
actual measurements of the centerline velocity $V_{e_{\text {mingrax }}}$ by Pitot tube, they obtained an actual average velocity from the equation

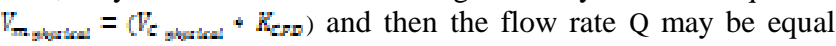
$Q=\left(V_{m_{\text {panas }}} \times A\right)$ The study showed an alternative way for computational flow rate based on centerline axial velocity measured using Pitot tube and the correction factor obtained from velocity profile modeled with CFD. The CFD model used to predict the behavior of installation and allow measurement of actual flow rate.

This literature survey shows that the Pitot tubes are used widely in the water flow measurement and calibration of flow meter in water supply companies. The advantage of Pitot tubes is that they can be used for wide range of pipe diameters and they can be easily installed and do not require interruptions or removal of the measuring device, which allows the calibration of the flow meters in the field [12], [13]. Therefore, using Pitot tubes to measure the centerline axial velocity at different axial positions is a matter of practice. This review also indicates that the calibration coefficient $C_{a}$ is varying and depending on Reynolds number but in general $c_{a}=1$ is accepted for an ordinary flow of most practical 
engineering purposes. For low flow rates the $C_{d}$ value may be greater than 1.0 because of the viscosity effect.

\section{GOVERNING EQUATIONS}

The flow is considered to be incompressible, steady, and the fluid flows symmetrically in the pipe. The two dimensions of governing equations are:

The continuity equation

$\frac{\partial\left(v_{x}\right)}{\partial x}+\frac{1}{y} \frac{\partial\left(r v_{r}\right)}{\partial y}=0$

The momentum equations

X-component

$\rho\left(v_{x} \frac{\partial v_{x}}{\partial x}+v_{r} \frac{\partial v_{x}}{\partial r}\right)=-\frac{\partial p}{\partial x}+\mu\left(\frac{1}{r} \frac{\partial}{\partial r}\left(r \frac{\partial v_{x}}{\partial r}\right)+\frac{\partial v_{x}}{\partial x^{2}}\right)$

r-component

$$
\rho\left(v_{x} \frac{\partial v_{r}}{\partial x}+v_{r} \frac{\partial v_{r}}{\partial r}\right)=-\frac{\partial p}{\partial r}+\mu\left(\frac{1}{\partial} \frac{\partial}{\partial r}\left(r \frac{\partial v_{r}}{\partial r}\right)+\frac{\partial v_{r}}{\partial x^{2}}\right)
$$

The energy equation

$$
\begin{aligned}
\rho C_{p}\left(v_{x} \frac{\partial T}{\partial x}+v_{r} \frac{\partial T}{\partial y}\right) & =-p \operatorname{div} v+\left(\tau_{x x} \frac{\partial v_{x}}{\partial x}+\tau_{r x} \frac{\partial v_{x}}{\partial y}+\right. \\
& \left.\tau_{x y} \frac{\partial v_{r}}{\partial x}+\tau_{r y} \frac{1}{\partial} \frac{\partial\left(v_{\gamma}\right)}{\partial r}\right)+\operatorname{div}\left(K_{f} \text { grad } T\right)
\end{aligned}
$$

where $v_{\mathrm{X}}$ and $v_{\mathrm{r}}$ are the velocity components in $x$ and $r$ directions respectively, $\rho$ is the density of fluid, $p$ is the static pressure, $\mu$ is the fluid viscosity, $C_{v}$ is the specific heat at constant pressure, $T$ is the absolute temperature, $v$ is fluid velocity in the spatial coordinate, $\tau_{m,}, \tau_{r z}, \tau_{m x}$ and $\tau_{r r}$ are the viscous stresses and $K_{f}$ is the thermal conductivity of fluid. The CFD simulations were based upon the standard twoequation $\mathrm{k}-\varepsilon$ turbulence model which is the most suitable for turbulent flows in a channel or pipe flow [14].

\section{MODELING DETAILS}

The geometry of the presented two-dimensional problem is shown in Figure 5. The pipe boundaries consist of a wall, centerline axis, inlet, and outlet. The inlet pipe to the test section has a length $L_{a}$ with diameter $\mathrm{d}$ followed by a diffuser section of length $L$ while the tail straight pipe of the test section has a length $L_{v}$ with diameter $D$. The reference point of the $\mathrm{x}$-axis origin starts at the end of the diffuser. The dimensions of the test section are listed in Table 1.

Table 1. Dimensions of the test section

\begin{tabular}{|c|c|}
\hline \multicolumn{2}{|c|}{ Pipe } \\
\hline Diameter $d$ & $1.905 \mathrm{~cm}(0.75$ inch $)$ \\
\hline Diameter $D$ & $3.810 \mathrm{~cm}(1.5 \mathrm{inch})$ \\
\hline Length $L_{d}$ & $15 \mathrm{~cm}$ \\
\hline Length $L_{s}$ & $165 \mathrm{~cm}$ \\
\hline Length $L$ & $5 \mathrm{~cm}$ \\
\hline
\end{tabular}

The mesh generation and size are an important step to control the time-consumption of the CFD simulation. The grid independence test and its reflection on the centerline velocity of the fully developed flow with several grid sizes from coarse to very fine mesh are listed in Table 2 .
Table 2. Mesh independence of computational domain

\begin{tabular}{|c|c|c|c|}
\hline $\begin{array}{c}\text { Grid } \\
\text { no. }\end{array}$ & $\begin{array}{c}\text { Gird } \\
\text { size }(\mathbf{m})\end{array}$ & $\begin{array}{c}\text { No. of } \\
\text { meshing } \\
\text { element }\end{array}$ & $\begin{array}{c}\text { Centerline velocity } \\
\text { of a fully developed } \\
\text { region }(\mathbf{m} / \mathbf{s})\end{array}$ \\
\hline 1 & $1.59 \mathrm{E}-03$ & 53756 & 1.472 \\
\hline 2 & $1.06 \mathrm{E}-03$ & 94538 & 1.476 \\
\hline 3 & $9.07 \mathrm{E}-04$ & 119398 & 1.482 \\
\hline 4 & $7.93 \mathrm{E}-04$ & 144092 & 1.482 \\
\hline
\end{tabular}

The variation of centerline axial velocity $V_{\mathrm{esn}}$ of the four mesh cases is plotted along the x-direction of the tail straight pipe $L_{D}$ of test section compared with each other as shown in Figure 2, where the plot begins with $\boldsymbol{x}=23 \mathrm{~cm}$. The results of the mesh independence test should follow the similarity of the nearest value. The two finest grid distribution seems to follow the same tendency in a sufficient manner. It has assumed that the grid with $N=119398$ is sufficient for acceptable accuracy of the solution. The grid distribution is displayed for the geometry of the test section in Figure 3.

Adequate boundary conditions which describe the fluid flow physics must be defined in the CFD solver. For the inlet boundary, the computed initial values of the velocity for each flow rate are indicated in table 3. For the outlet boundary of the model, the value of outlet gauge pressure is considered $100 \mathrm{kPa}$ as the mean value. The wall is stationary, no-slip conditions are applied. The centerline is set to be the $\mathrm{x}$-axis, where the origin starts from the end of the diffuser. The water is used as a working fluid.

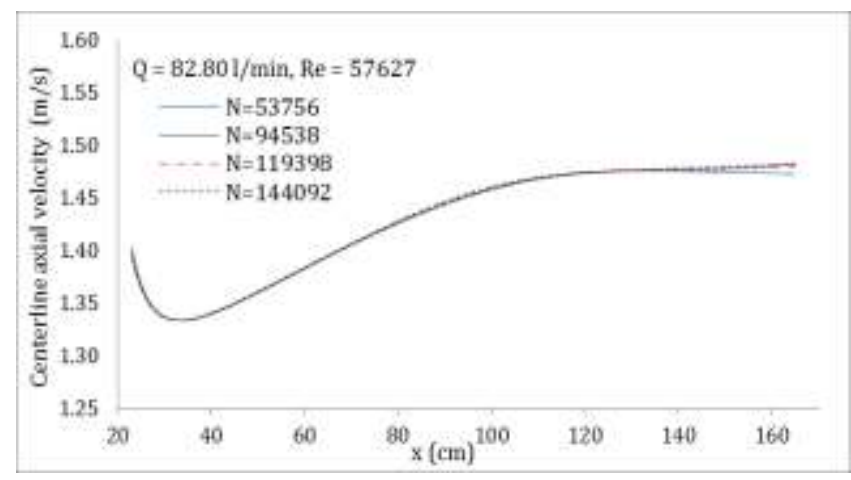

Figure 2 Comparison of centerline axial velocity development for different meshes

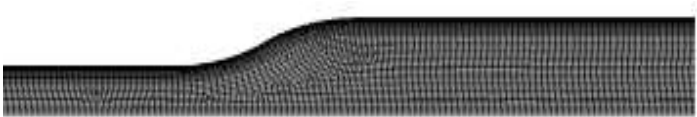

Figure 3 Mesh distribution of computational domain

\section{EXPERIMENTAL WORK}

A schematic diagram of the used facility to perform the experiments is shown in Figure 5. The system consists of a closed loop circuit. The main components of the system are storage tank, centrifugal pump, flow meter, and test section. The electric heater is located inside the stainless steel storage tank. The fluid is circulated in a closed loop by stainless steel centrifugal pump of 750-watt motor power. A positive displacement flow meter was used to measure the flow rate. The test section is placed between a reference positive displacement meter and meter under test. Five L-type Pitot tubes were installed at five different positions to 
measure centerline axial velocity as shown in Figure 6 and Figure 7 . The pitot tubes are connected to an inverted U-tube manometer.

The variation of centerline axial velocity was investigated under unheated and heated conditions through the tail straight pipe of test section. The hydrodynamic entrance length $L_{s}$ to a fully developed region has been determined downstream of diffuser section, where $L_{s}$ starts at the tail straight pipe inlet of test section, just after the end of the diffuser section where $x$ is taken to be zero. This study was carried for three cases of flow rates related to the orifice size of the valve. Case I refers to $34 \%$ valve opening, case II refers to $51 \%$ valve opening, case III refers to a fully opening of the valve. For each case, two flow rates are measured corresponding to the same valve opening, one for unheated conditions and one for heated conditions as shown in

Table 3. The temperature of the water $T$ is the main difference between unheated and heated conditions. Its impact on the flow rate and Reynolds number is shown in Figure 8 and Figure 9 respectively.

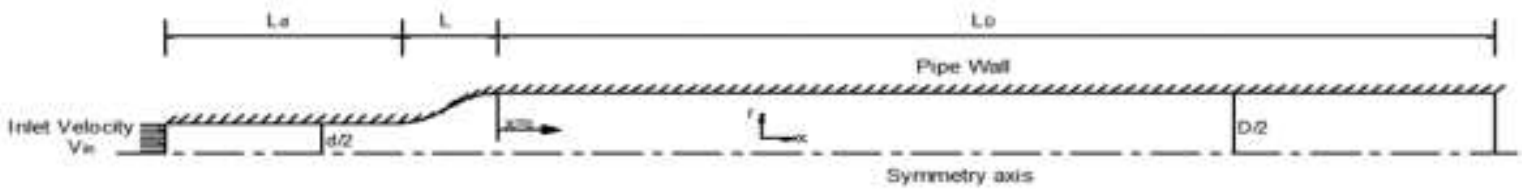

Figure 4. Line diagram of the computational domain

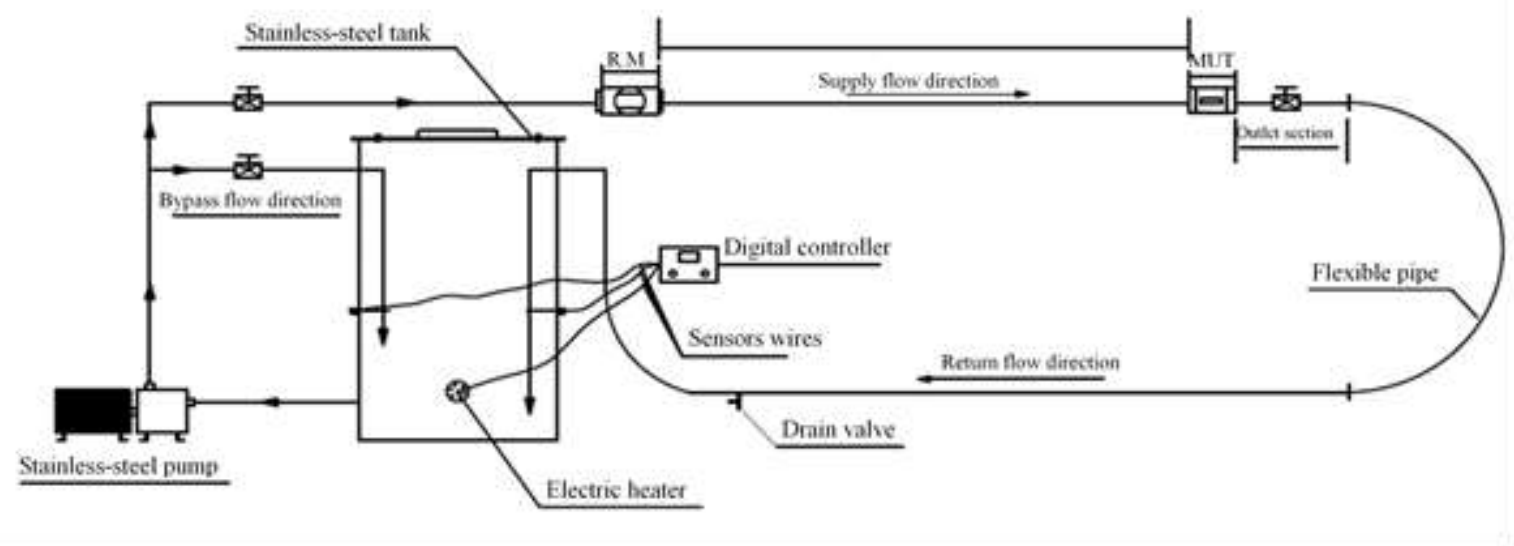

Figure 5. Schematic diagram of the flow meter calibration system.

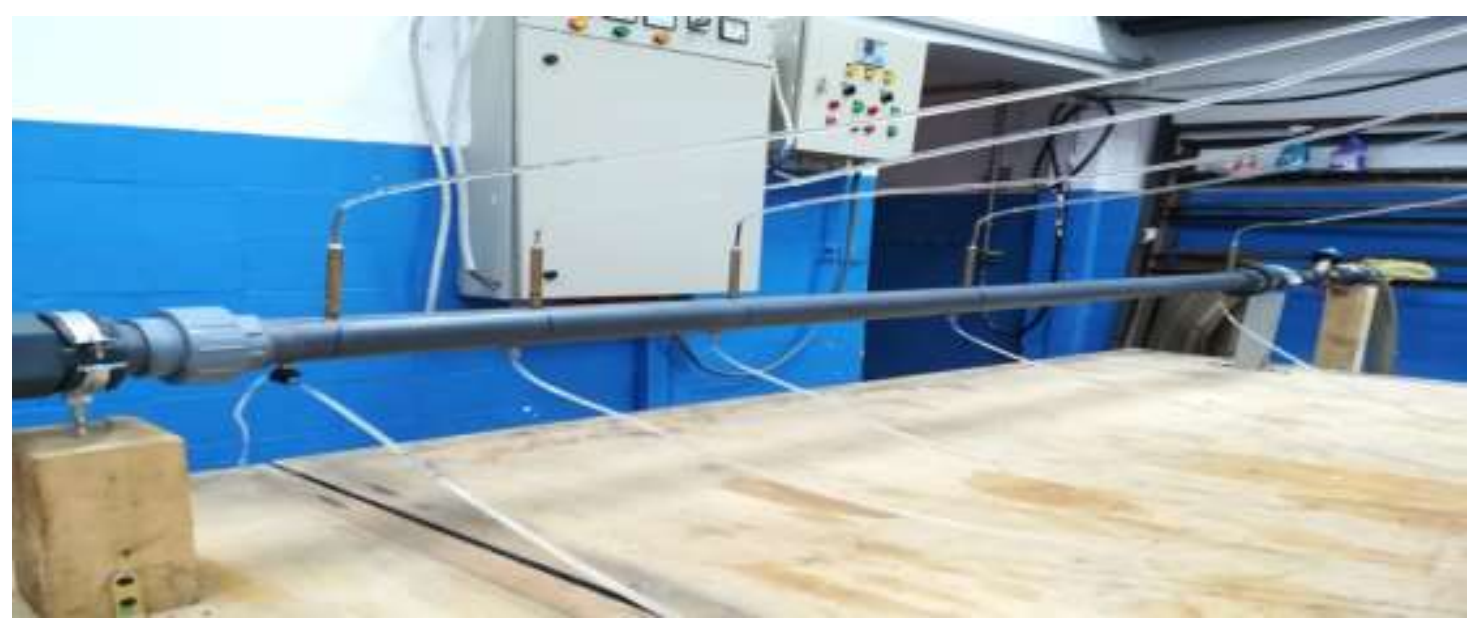

Figure 6.Test section.

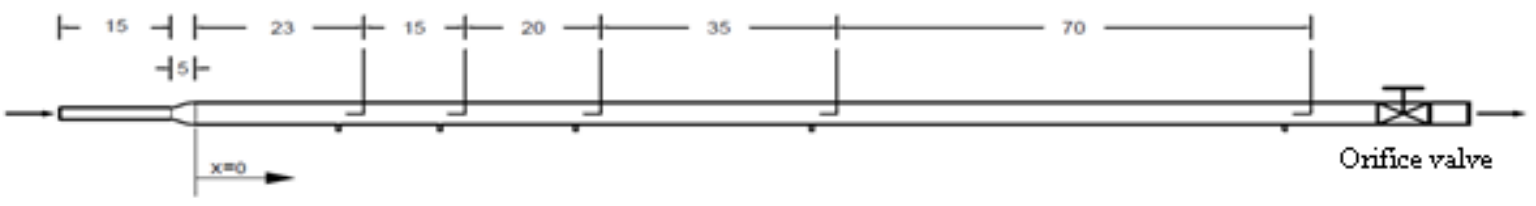

Figure 7. The layout of the test section 
Table 3. Flow characteristics

\begin{tabular}{|c|c|c|c|c|}
\hline \multicolumn{2}{|c|}{ Case } & I & II & III \\
\hline \multicolumn{2}{|c|}{ Valve opening (\%) } & 34 & 51 & 100 \\
\hline $\begin{array}{c}\text { Measured flow rate } \\
\text { Q (1/min) }\end{array}$ & Unheated & 60.30 & 71.10 & 82.80 \\
\cline { 2 - 5 } & Heated & 61.40 & 72.90 & 84.90 \\
\hline $\begin{array}{c}\text { Average inlet velocity } \\
V_{\text {in }}(\mathrm{m} / \mathrm{s})\end{array}$ & Unheated & 3.53 & 4.16 & 4.84 \\
\cline { 2 - 6 } & Heated & 3.59 & 4.26 & 4.97 \\
\hline $\begin{array}{c}\text { Reynolds number } R e \\
R V_{\mathrm{in}} d\end{array}$ & Unheated & 41967 & 49484 & 57627 \\
\cline { 2 - 6 } & Heated & 72191 & 85712 & 99821 \\
\hline
\end{tabular}

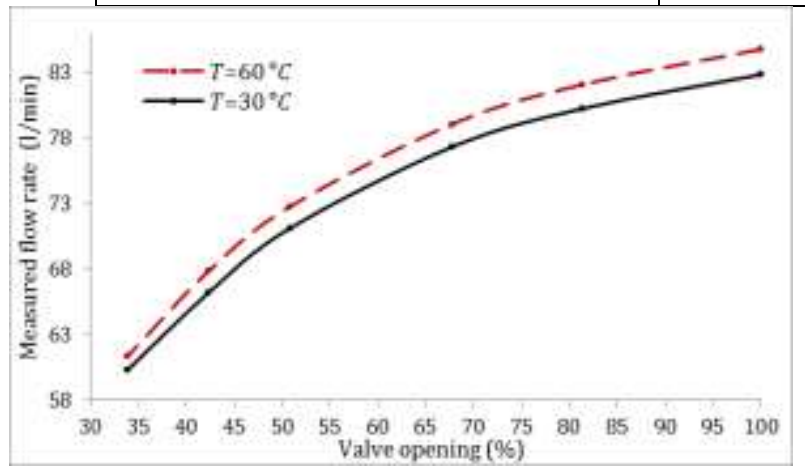

Figure 8. Measured flow rate versus orifices of the valve.

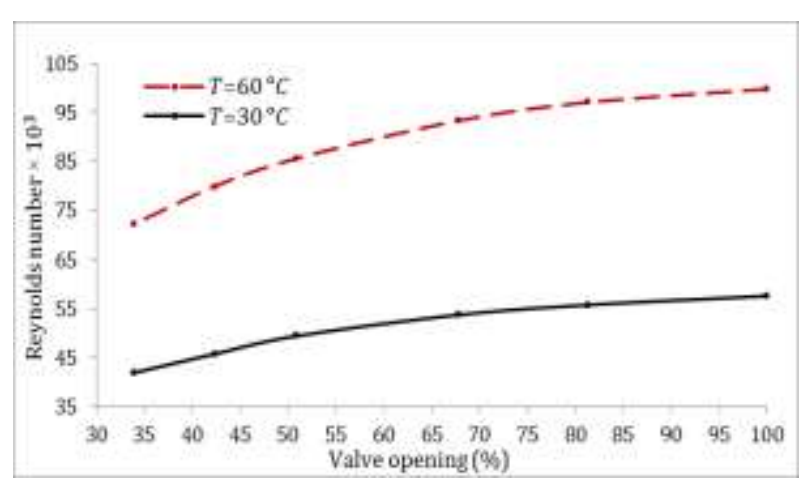

Figure 9. Reynolds number versus orifices of the valve for unheated and heated conditions.

The test procedures during the experiments are described as follows:

1. The tank was filled with working fluid.

2. The fluid was heated by using an electric heater to raise its temperature up to the required value. To compensate any heat losses a digital controller was used to set and preserve the fluid temperature at a constant value.

3. The pump was turned on and the fluid was forced through the closed loop circuit.

4. The positive displacement flow meter was adjusted to measure the flow rate. The desired flow rate was achieved using the orifice valve.

5. After steady-state conditions were achieved and during the test run, the fluid temperature in the test section was recorded using thermocouples, the center line axial velocity was recorded using Pitot tubes and the average flow rate was recorded using a positive displacement meter. All these parameters were recorded simultaneously.

6 . The same procedures were repeated for all cases at different temperatures.

\section{RESULTS AND DISCUSSION}

The development of centerline axial velocity was measured experimentally along the tail straight pipe of test section at five different axial positions and compared with the numerical results. The flow enters the test section with specified velocity and then the centerline axial velocity decreases dramatically due to enlargement of diameter, and then increases gradually to reach asymptotically a constant value at the so-called fully developed flow.

The variation of centerline axial velocity for unheated conditions is presented experimentally and numerically in Figure 10, where the flow rate was $60.30 \mathrm{l} / \mathrm{min}$ and Reynolds number was 41967 . The fully developed experimental centerline axial velocity is 1.04 $\mathrm{m} / \mathrm{s}$ while the computed numerical value is equal to $1.09 \mathrm{~m} / \mathrm{s}$. It was observed that the location of fully developed region starts approximately at $L_{s}=117 \mathrm{~cm}$. For heated condition, where the measured flow rate was $61.40 \mathrm{l} / \mathrm{min}$ and Reynolds number was 72191 for the same valve opening as unheated case, the centerline axial velocity is presented in Figure 11 and Figure 12. The effect of heating on the centerline axial velocity is very small. The fully developed experimental centerline axial velocity is $1.03 \mathrm{~m} / \mathrm{s}$ while the computed numerical value is equal to $1.09 \mathrm{~m} / \mathrm{s}$. It was observed that the hydrodynamic entrance length $L_{z}$ has been increased to more than $142 \mathrm{~cm}$ downstream of the expansion section due to the heating effect.

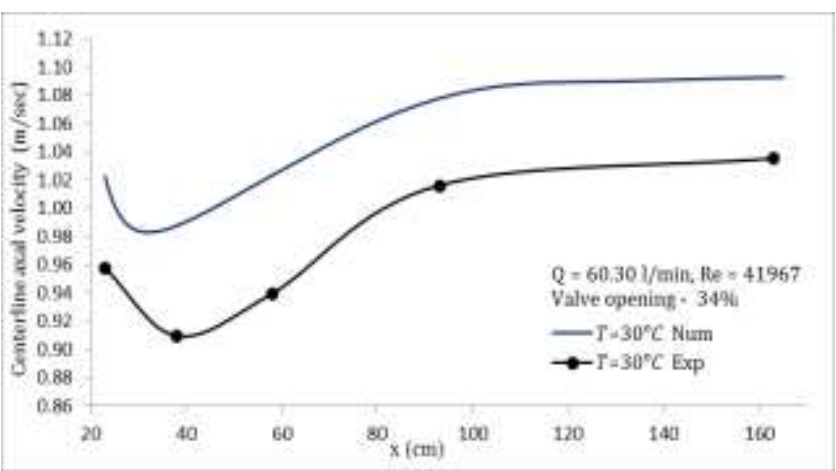

Figure 10. Centerline axial velocity development for unheated conditions of Case I. 


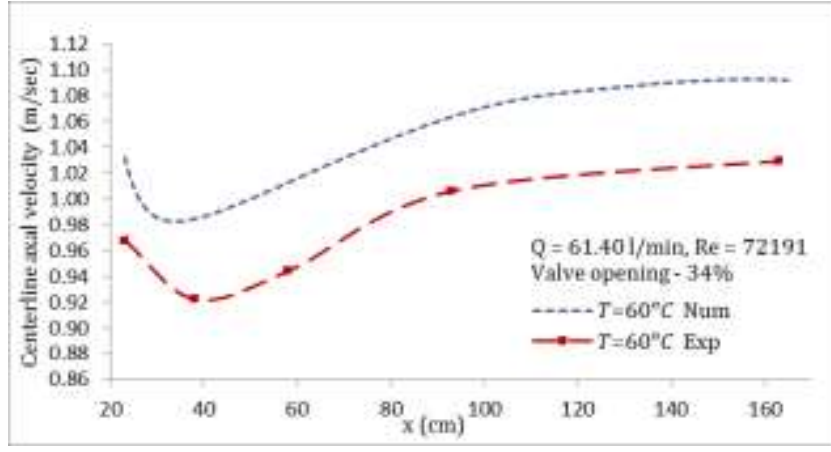

Figure 11. Centerline axial velocity development for heated conditions of Case I.

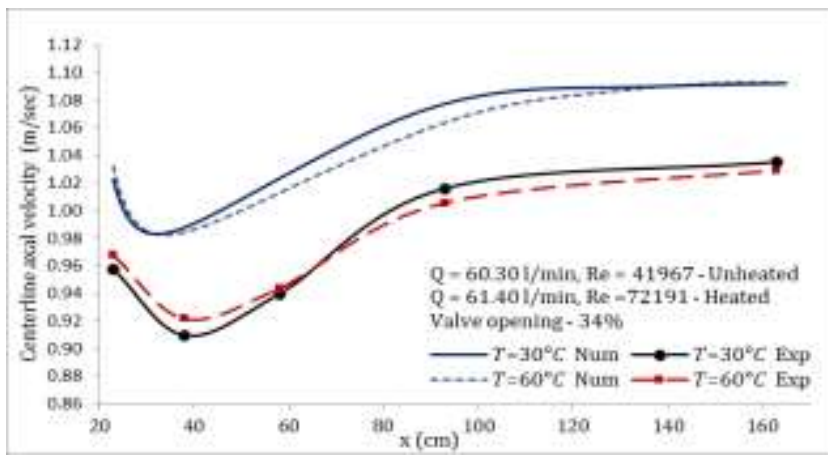

Figure 12. Centerline axial velocity development for unheated and heated conditions of Case I.

The variation of centerline axial velocity for unheated and heated conditions of case II is presented experimentally and numerically in Figure 13. For unheated conditions, where the flow rate was $71.10 \mathrm{l} / \mathrm{min}$ and Reynolds number was 49484 , the fully developed experimental centerline axial velocity is $1.22 \mathrm{~m} / \mathrm{s}$ while the computed numerical value is equal to 1.28 $\mathrm{m} / \mathrm{s}$. It was observed that the location of a fully developed region starts approximately at $L_{s}=121 \mathrm{~cm}$. For heated conditions, where the flow rate was $72.901 / \mathrm{min}$ and Reynolds number was 85712 for the same valve opening as unheated case, the effect of heating is extremely small on the centerline axial velocity. The fully developed experimental centerline axial velocity is $1.21 \mathrm{~m} / \mathrm{s}$ while the computed numerical value is equal to $1.28 \mathrm{~m} / \mathrm{s}$. It was observed that the hydrodynamic entrance length has been increased to more than $144 \mathrm{~cm}$ downstream of the expansion section due to heating effect.

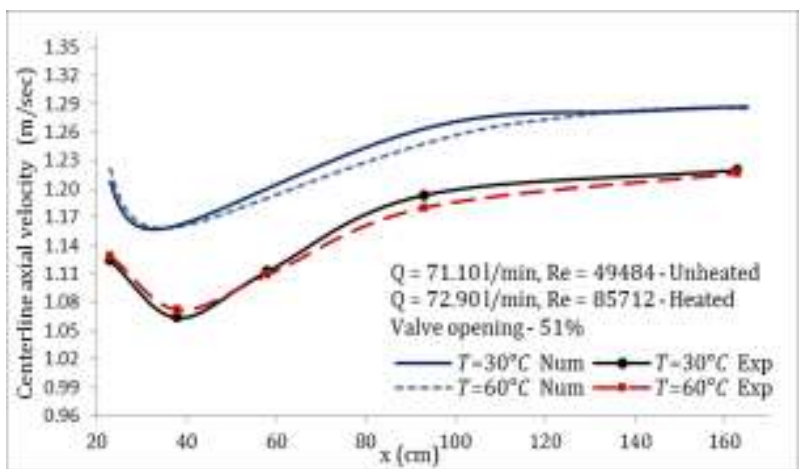

Figure 13. Centerline axial velocity development for unheated and heated conditions of Case II.

The variation of centerline axial velocity for unheated and heated conditions of case III is presented experimentally and numerically in Figure 14. For unheated conditions, where the flow rate was 82.80 1/min and Reynolds number was 57627 .
The fully developed experimental centerline axial velocity is 1.36 $\mathrm{m} / \mathrm{s}$ while the computed numerical value is equal to $1.48 \mathrm{~m} / \mathrm{s}$. It was observed that the location of a fully developed region starts approximately at $L_{s}=133 \mathrm{~cm}$. For heated conditions, where the flow rate was $84.9 \mathrm{l} / \mathrm{min}$ and Reynolds number was 99821 for the same valve opening as unheated case, the effect of heating is also extremely small on the centerline axial velocity. The fully developed experimental centerline axial velocity is $1.38 \mathrm{~m} / \mathrm{s}$ while the computed numerical value is equal to $1.49 \mathrm{~m} / \mathrm{s}$. It was observed that the hydrodynamic entrance length has been increased to more than $154 \mathrm{~cm}$ downstream of the expansion section due to the heating effect.

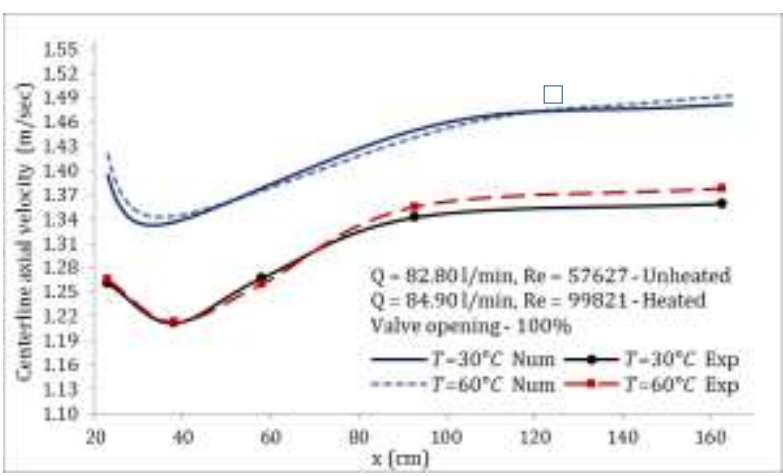

Figure 14. Centerline axial velocity development for unheated and heated conditions of Case III.

The change of the hydrodynamic entrance lengths $L_{z}$ is determined from $x=0$ as a function of the measured flow rate for all cases as presented in Figure 15. It is observed that for heated cases, $L_{z}$ was increased by $21.4 \%$ for case I, $19.5 \%$ for case II, and $16.1 \%$ for case III. The increase of the flow rates due to heating is about $1.7 \%$ to $2.3 \%$ for all cases.

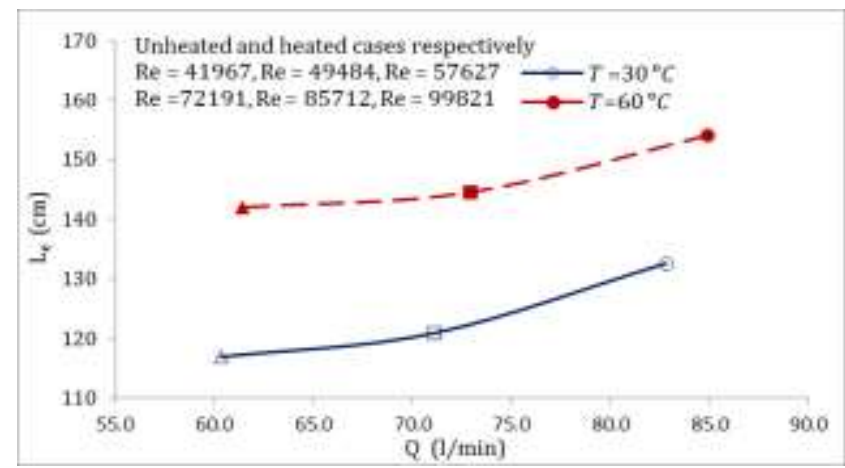

Figure 15. Hydrodynamic entrance length $L_{z}$ as a function of measured flow rate (Indirectly valve opening) for heated and unheated conditions. case I $(\triangle)$, Case II ( ), Case III $(\bigcirc)$. Open symbols: unheated conditions; filled symbols: heated conditions.

\section{CONCLUSION}

An experimental and numerical study was conducted to investigate the influence of heat on the hydrodynamic entrance length of developing pipe flow. The development of centerline velocity is presented at different axial positions throughout the tail straight pipe of test section by measurements carried out experimentally using Pitot tube and computed numerically using ANSYS FLUENT 16 software code. Flows were simulated with a lengthy tail pipe $L_{D}$ to cover the developing and fully developed flow region. The measurements were conducted for various flow rates in case absence and presence of heat. It was found that the computational results show a good trend agreement with the 
experimental results. The results have been shown that the influence of heat on density and viscosity lead to increasing flow rate and Reynolds number, that is why the hydrodynamic entrance length has been increased. The $L_{x}$ increased by $21.4 \%$ for case I, $19.5 \%$ for case II and $16.1 \%$ for case III. The results also show that the magnitude of the centerline axial velocity for the fully developed region under heated conditions has been changed slightly compared to unheated conditions. For heated water up to $60^{\circ} \mathrm{C}$, the recommended distance of the hydrodynamic entrance length is equal to 45D, it has been determined as a proper placement of the measuring device to measure the flow rate accurately for all cases.

\section{Nomenclature}

$\begin{array}{ll}Q & \text { Measured flow rate } \\ A & \text { Cross section area } \\ v_{X} & \text { Component of velocity in x direction } \\ v_{Y} & \text { Component of velocity in y direction }\end{array}$

\section{REFERENCES}

[1] F. Durst, S. Ray, B. Ünsal, and O. A. Bayoumi, "The Development Lengths of Laminar Pipe and Channel Flows," J. Fluids Eng., vol. 127, no. 6, p. 1154, 2005.

[2] Shah R. K. and London A. L., "Laminar flow forced convection in ducts," (Academic Press. 1978).

[3] A. G. Darbyshire and T. Mullin, "Transition to turbulence in constant-mass-flux pipe flow," J. Fluid Mech., vol. 289, no. 1995, pp. 83-114, 1995.

[4] M. W. Collins and M. Keynejad, "Effects of temperature-dependence of viscosity and viscous dissipation on laminar flow heat transfer in circular tubes," Int. J. Heat Fluid Flow, vol. 4, no. 1, pp. 3342, 1983 .

[5] Shivani T. Gajusingh and M. H. K. Siddiqui, "The influence of wall heating on the flow structure in the near-wall region," Int. J. Heat Fluid Flow, vol. 29, no. 4, pp. 903-915, 2008.

[6] C. I. H. Nicholl, "Some dynamical effects of heat on a turbulent boundary layer," J. Fluid Mech., vol. 40, no. 2, pp. 361-384, 1970.

[7] F. Keisuke and N. Masamoto, "Unstable stratification effects on turbulent shear flow in the wall region," Int. J. Heat Mass Transf., vol. 28, no. 12, pp. 2343-2352, 1985.

[8] R. J. Lynn, I. V Haljasmaa, F. Shaffer, R. P. Warzinski, and J. S. Levine, "A Pitot tube system for obtaining water velocity pro fi les with millimeter resolution in devices with limited optical access," Flow Meas. Instrum., vol. 40, pp. 50-57, 2014.

[9] S. K. S. Boetcher and E. M. Sparrow, "Limitations of the standard Bernoulli equation method for evaluating Pitot/impact tube data," Int. J. Heat Mass Transf., vol. 50, no. 3-4, pp. 782-788, 2007.

[10] I. D. O. Buscarini, A. C. Barsaglini, P. J. S. Jabardo, N. M. Taira, and G. Nader, "Impact of Pitot tube calibration on the uncertainty of water flow rate measurement," J. Phys. Conf. Ser., vol. 648, no. 1, pp. 0-10, 2015.

$\begin{array}{ll}v & \text { Fluid velocity in the spatial coordinate } \\ x & \text { Axial coordinate along the pipe } \\ r & \text { Radial coordinate across the pipe } \\ C_{p} & \text { Specific heat at constant pressure } \\ T & \text { Absolute temperature of fluid } \\ \tau_{x x}, \tau_{\mathrm{Tr}}, . & \text { Viscous stresses } \\ K_{f} & \text { Thermal conductivity of fluid } \\ N & \text { Number of Meshing element } \\ L_{d} & \text { length of the inlet pipe } \\ L & \text { length of the diffuser section } \\ L_{D} & \text { length of the tail straight pipe } \\ D & \text { Diameter of the tail straight pipe } \\ d & \text { diameter of the inlet pipe } \\ R e & \text { Reynolds number } \\ \rho & \text { Density of fluid } \\ V_{\text {in }} & \text { Average inlet velocity } \\ \mu & \text { Dynamic viscosity of fluid } \\ L_{e} & \text { Hydrodynamic entrance length }\end{array}$

[11] A. Sotero and B. M. Brentan, "Water Supply Flow Measurement Using Experimental Data and CFD Modeling," WDSA / CCWI Jt. Conf. 2018, vol. 1, no. July, 2018.

[12] ISO 3966:2008, "Measurement of fluid flow in closed conduits -Velocity area method using Pitot static tubes," Int. Organ. Stand. - ISO, Geneva, Switzerland, 2008.

[13] O. S. Y. and N. M. T. G. Nader, "Analise da influência da mudança de ângulos de Roll e Yaw de tubo de Pitot Cole na medição da velocidade do escoamento," II Int. Congr. Mech. Metrol. Natal, Brazil, Novemb. 27-30, 2011.

[14] M.B Abboth and D.R Basco, "COMPUTATIONAL FLUID DYNAMICS; AN INTRODUTION FOR ENGINEERS,” Longman Sci. Tech., 1994. 